\title{
Zingiber officinale Improves Cognitive Function of the Middle-Aged Healthy Women
}

\section{Naritsara Saenghong, ${ }^{1}$ Jintanaporn Wattanathorn, ${ }^{2}$ Supaporn Muchimapura, ${ }^{2}$ Terdthai Tongun, ${ }^{2}$ Nawanant Piyavhatkul, ${ }^{3}$ Chuleratana Banchonglikitkul, ${ }^{4}$ and Tanwarat Kajsongkram ${ }^{4}$}

\author{
${ }^{1}$ Neuroscience Program and Graduate School, Faculty of Medicine, Khon Kaen University, Khon Kaen 40002, Thailand \\ ${ }^{2}$ Neuroscience Laboratory Unit, Department of Physiology, Faculty of Medicine, Khon Kaen University, Khon Kaen 40002, Thailand \\ ${ }^{3}$ Department of Psychiatry, Faculty of Medicine, Khon Kaen University, Khon Kaen 40002, Thailand \\ ${ }^{4}$ Department of Pharmaceutical and Natural Products, Thailand Institute of Scientific and Technological Research, \\ Pathumthani 12120, Thailand
}

Correspondence should be addressed to Jintanaporn Wattanathorn, jinwat05@gmail.com

Received 20 August 2011; Accepted 21 September 2011

Academic Editor: Angelo Antonio Izzo

Copyright () 2012 Naritsara Saenghong et al. This is an open access article distributed under the Creative Commons Attribution License, which permits unrestricted use, distribution, and reproduction in any medium, provided the original work is properly cited.

\begin{abstract}
The development of cognitive enhancers from plants possessing antioxidants has gained much attention due to the role of oxidative stress-induced cognitive impairment. Thus, this study aimed to determine the effect of ginger extract, or Zingiber officinale, on the cognitive function of middle-aged, healthy women. Sixty participants were randomly assigned to receive a placebo or standardized plant extract at doses of 400 and $800 \mathrm{mg}$ once daily for 2 months. They were evaluated for working memory and cognitive function using computerized battery tests and the auditory oddball paradigm of event-related potentials at three different time periods: before receiving the intervention, one month, and two months. We found that the ginger-treated groups had significantly decreased P300 latencies, increased N100 and P300 amplitudes, and exhibited enhanced working memory. Therefore, ginger is a potential cognitive enhancer for middle-aged women.
\end{abstract}

\section{Introduction}

Recent findings suggest that middle-aged women usually develop some form of cognitive impairment. It was found that middle-aged women performed poorly in various areas of cognitive function including attention, calculation and immediate recall (assessed using Minimental state examination (MMSE) ) [1]. Evidence has also shown that oxidative stress contributes to cognitive impairment as age advanced [2]. Due to the increase in the middle-aged population, an abundance of research has focused on the development of cognitive enhancers from medicinal plants reputed for antioxidant and cognitive enhancing effects. Ginger, or Zingiber officinale, a plant in the family of Zingiberaceae, has longterm been used as both a spice and as a medicine in Asian, Indian, and Arabian folklore. The rhizomes of Zingiber officinale exhibit a wide range of pharmacological properties including antilipidemia [3], antiemetic [4], antiinflammation, and antiarthritis [5]. According to Arabian folklore, ginger has been claimed to improve memory. Moreover, it has also been traditionally used as an ingredient for cognitive enhancement. Our preliminary data in Wistar rats showed that ginger rhizomes extract could enhance memory and protect against brain damage [6]. In addition, it was also reported to have antioxidant effects $[7,8]$. Based on the antioxidant and cognitive enhancing effects of ginger rhizomes extract, the present neuropsychological and electrophysiological study aims to determine the effect of ginger rhizomes extract on the cognitive function of middleaged women. 


\section{Materials and Methods}

2.1. Participants. Sixty healthy, Thai, middle-aged women (mean age $53.40 \pm 3.57$ years) were recruited to participate in the present study, which was approved by the Ethical Committee of the Faculty of Medicine at Khon Kaen University. Prior to investigation, each volunteer provided informed consent and completed the medical health questionnaire. Participants were also screened for physical health by a physician in order to assure healthy condition. Inclusion criteria were healthy, middle-aged, Thai National women between the ages of 50 and 60 residing in the Northeast Region of Thailand. Exclusion criteria included any history of cardiovascular disease, respiratory disease, neuropsychological disease, head injury, diabetes, cancer, alcohol addiction, and anyone who smoked more than 10 cigarettes per day because all mentioned conditions could produce the disturbance of cognitive function. Individuals taking prescribed, nonprescribed drugs, or nutraceutical compounds known to influence the function of the nervous system were excluded. Participants were randomly divided into 3 separate groups: placebo, Zingiber officinale $400 \mathrm{mg}$, and Zingiber officinale $800 \mathrm{mg}$.

2.2. The Preparation of the Standardized Extract of Zingiber officinale. A standardized extract of Zingiber officinale was prepared by the Thailand Institute of Scientific and Technological Research in Pathum Sthani, Thailand. Standardization and conformity of the extract were assured by strict inprocess controls during manufacture and complete analytical control of the resulting dry extract. In brief, the dried ginger rhizome powder was extracted with 95\% ethanol in a stainless steel tank for 5 to 10 days. The filtrate was evaporated to dryness under a vacuum at $35^{\circ} \mathrm{C}$ on a rotary evaporator. The production yield of the extract was $6.84 \%$ $\mathrm{w} / \mathrm{w}$. The phenolic compound of standardized ginger extract contained $7.33 \% \mathrm{w} / \mathrm{w}$ of 6 -gingerol and $1.34 \% \mathrm{w} / \mathrm{w}$ of 6 shogaol.

2.3. Procedures and Treatments. This study was 2 months in duration and was double blind, placebo controlled, and arranged with randomized trials. A random list of numbers was computer-generated. After being randomly assigned to treatment groups, each participant received one capsule of either the placebo or ginger extract (400 or $800 \mathrm{mg}$ ) once daily. The selected doses of $Z$. officinale are based on the dosage range that produces cognitive enhancing effect in animal model and the safety range. The placebo and ginger capsules had the same color, texture, size, and odor. All participants were screened for baseline intellectual function using standard progressive matrices (SPMs) in order to avoid confounding error induced by the intellectual function problem. Participants were assessed for cognitive performance after 1 and 2 months of treatment. According to the evaluation, all experimenters and staff were instructed to follow a strict protocol and were told not to discuss any issues related to the use of medication. The medication compliance was monitored by interview and counting the remaining medication, and the side effect was assessed via interview, self-report, and physical exam in each visit. Subjects were requested to call the study center if they experienced any medical problems during the 60 days of study duration. At the end of the study, they were also asked about any adverse experiences.

\subsection{Event-Related Potentials (ERPs)}

2.4.1. ERP Recording. All subjects were assessed for cognitive performance using the classic "oddball paradigm" of auditory event-related potentials (N100 and P300 amplitudes and latencies) [9]. The electroencephalogram (EEG) was recorded via $\mathrm{Cz}$, and linked mastoids were used as reference for the electrode. The resistance of the electrodes was kept below $5 \mathrm{kohm}$. The analog filter band pass was $1-100 \mathrm{~Hz}$ [10]. For each stimulus, an epoch of $500 \mathrm{~ms}$ duration including a $100 \mathrm{~ms}$ prestimulus period was extracted from the continuous EEG. Epochs with a voltage change below $0.1 \mu \mathrm{V}$ or above $70 \mu \mathrm{V}$ were rejected from further analysis.

2.4.2. ERP Measurement. The subjects listened to a train of tone bursts presented binaurally through headphones. The standard stimuli had a tonal frequency of $650 \mathrm{~Hz}$ $(60 \mathrm{~dB}, 200 \mathrm{~ms})$ and occurred with a tonal frequency of $80 \%$. The target stimuli had a tonal frequency of $1 \mathrm{kHz}$ $(60 \mathrm{~dB}, 200 \mathrm{~ms})$ and occurred with a probability of $20 \%$. All participants were informed to pay attention and mentally count infrequent target tones. Interstimulus intervals varied randomly between 1250 and $3000 \mathrm{~ms}$. The N100 latency range was determined to be $65-135 \mathrm{~ms}$, and the P300 latency range was determined to be $280-375 \mathrm{~ms}$. Both the latency and maximum amplitudes were measured for N100 and P300 deflections. Any peaks outside of this range were measured manually, and all peaks were visually examined prior to measurement.

2.5. Computerized Assessment Battery Test. The computerized assessment battery test was modified from the CDR computerized assessment battery test used in hundreds of European and North American drug trials which have been previously reported to be sensitive to acute cognitive improvements as well as impairments with a wide variety of substances $[11,12]$. Presentation was performed using notebook computers with a high-resolution VGA colour monitor, and, with the exception of written word recall tests, all responses were recorded via a two-button (yes/no) response box. The entire selection of tasks took approximately $20 \mathrm{~min}$. Tests were administered in the following order: word presentation, picture presentation, simple reaction time, digit vigilance task, choice reaction time, spatial working memory, numeric working memory, delayed word recognition, and delayed picture recognition.

Word Presentation. Fifteen words, matched for frequency and concreteness, were presented in sequence on the monitor for the participant to remember. The stimulus duration was $1 \mathrm{~s}$, as was the interstimulus interval. 
Picture Presentation. A series of 20 photographic images was presented on the monitor at the rate of 1 every $3 \mathrm{~s}$, with a stimulus duration of $1 \mathrm{~s}$, for the participant to remember.

Simple Reaction Time. The participant was instructed to press the "yes" response button as quickly as possible every time the word "yes" was presented on the monitor. Fifty stimuli were presented with an interstimulus interval that varied randomly between 1 and $3.5 \mathrm{~s}$. Reaction times were recorded in milliseconds.

Digit Vigilance Task. A target digit was randomly selected and constantly displayed to the right of the monitor screen. A series of digits was presented in the centre of the screen at the rate of $80 / \mathrm{min}$, and the participant was required to press the "yes" button as quickly as possible every time the digit in the series matched the target digit. The task lasted $1 \mathrm{~min}$ and there were 15 stimulus-target matches. Task measures were accuracy (\%), reaction time (milliseconds), and false alarms.

Choice Reaction Time. Either the word "no" or the word "yes" was presented on the monitor, and the participant was required to press the corresponding button as quickly as possible. There were 50 trials of which the stimulus word was chosen randomly with equal probability, with a randomly varying interstimulus interval between 1 and $3.5 \mathrm{~s}$. Reaction times (millisecond) and accuracy (\%) were recorded.

Spatial Working Memory. A pictorial representation of a house was presented on the screen with four of its nine windows lit. The participant was instructed to memorize the position of the illuminated windows. In 36 subsequent presentations of the house, one of the windows was illuminated, and the participant decided whether or not this matched one of the lighted windows in the original presentation. The participant made their response by pressing the "yes" or "no" response button as quickly as possible. Mean reaction times were measured in milliseconds, and the accuracy of responses to both original and novel (distractor) stimuli was recorded as percentages used to derive a "percentage greater than chance performance" score.

Numeric Working Memory. Five digits were presented sequentially for the participant to hold in memory. This was followed by a series of 30 probe digits for each of which the participant decided whether or not it had been in the original series and pressed the "yes" or "no" response button as appropriate and as quickly as possible. This was repeated two further times with different stimuli and probe digits. Mean reaction times were measured in milliseconds, and the accuracy of responses to both original and novel (distractor) stimuli was recorded as percentages that were used to derive a "percentage greater than chance performance" score.

Delayed Word Recognition. The original words and 15 distractor words were presented one at a time in randomized order. For each word, the participant indicated whether or not she recognized it as being included in the original
TABLE 1: Demographic data of subjects ( $n=20 /$ group).

\begin{tabular}{lccc}
\hline Baseline data & Placebo & $400 \mathrm{mg}$ & $800 \mathrm{mg}$ \\
\hline Age (years) & $53.92 \pm 3.82$ & $54.33 \pm 4.12$ & $54.33 \pm 3.17$ \\
Education (years) & $5.50 \pm 3.70$ & $5.40 \pm 3.68$ & $5.15 \pm 2.74$ \\
Full scale IQ & $98.95 \pm 4.42$ & $99.75 \pm 4.23$ & $98.85 \pm 6.01$ \\
Blood sugar & $90.06 \pm 8.45$ & $89.10 \pm 13.08$ & $91.15 \pm 10.16$ \\
$\begin{array}{l}\text { Body mass index } \\
\text { Blood pressure }\end{array}$ & $21.95 \pm 1.90$ & $22.78 \pm 2.06$ & $23.12 \pm 1.83$ \\
$\begin{array}{l}\text { systolic (mmHg) } \\
\begin{array}{l}\text { Blood pressure } \\
\text { diastolic (mmHg) }\end{array}\end{array}$ & $82.25 \pm 2.53$ & $82.80 \pm 2.73$ & $80.50 \pm 3.73$ \\
$\begin{array}{l}\text { Menstrual cessation } \\
\text { (years) }\end{array}$ & $3.95 \pm 1.60$ & $3.75 \pm 1.48$ & $4.05 \pm 1.57$ \\
\hline
\end{tabular}

Data were presented as mean \pm SD. $P$ and $F$ values were compared between groups.

list of words by pressing the "yes" or "no" button as appropriate and as quickly as possible. Mean reaction times were measured in milliseconds, and the accuracy of responses to both original and novel (distractor) stimuli was recorded as percentages that were used to derive a "percentage greater than chance performance" score.

Delayed Picture Recognition. The original pictures and 20 distractor pictures were presented one at a time in a randomized order. For each picture, participants indicated whether or not it was recognized as being from the original series by pressing the "yes" or "no" button as appropriate and as quickly as possible. Mean reaction times were measured in milliseconds, and the accuracy of responses to both original and novel (distractor) stimuli recorded as percentages that were used to derive a "percentage greater than chance performance" score.

To avoid learning effect on computerized battery test, the participants were assessed for working memory with different sets of parallel tests at the same difficulty level.

2.6. Statistical Analysis. Comparisons between doses were made using analysis of variance (ANOVA) and followed the recommendations of Keppel [13], with planned comparison being made between the placebo and each of the two active treatments utilizing $t$-tests. Statistical significance was regarded at $P$ value $<0.05$. In order to reject null hypothesis, the sample size justification and power analysis is considered.

Since the study is the preliminary study of clinical trial phase zero, the study is performed in accordance with the United States Food and Drug Administration's (FDA) 2006 Guidance on Exploratory Investigational New Drug (IND) Studies which suggests that the number of the sample size can be a small number approximately $10-15$ per group.

\section{Results}

3.1. Demographic Data of Subjects. The baseline demographic data for all participants is presented in Table 1. There were no significant differences found in demographic 


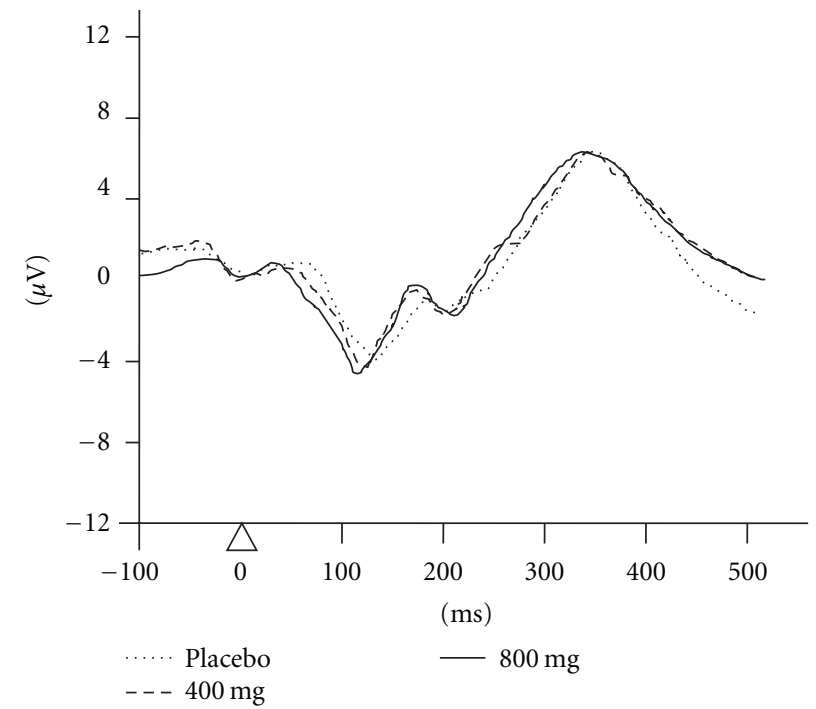

(a)

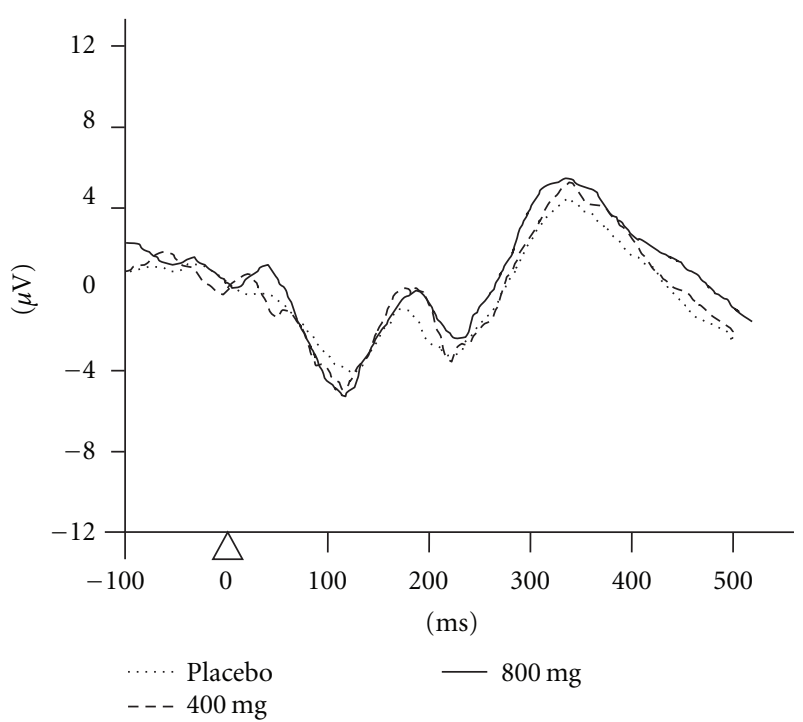

(b)

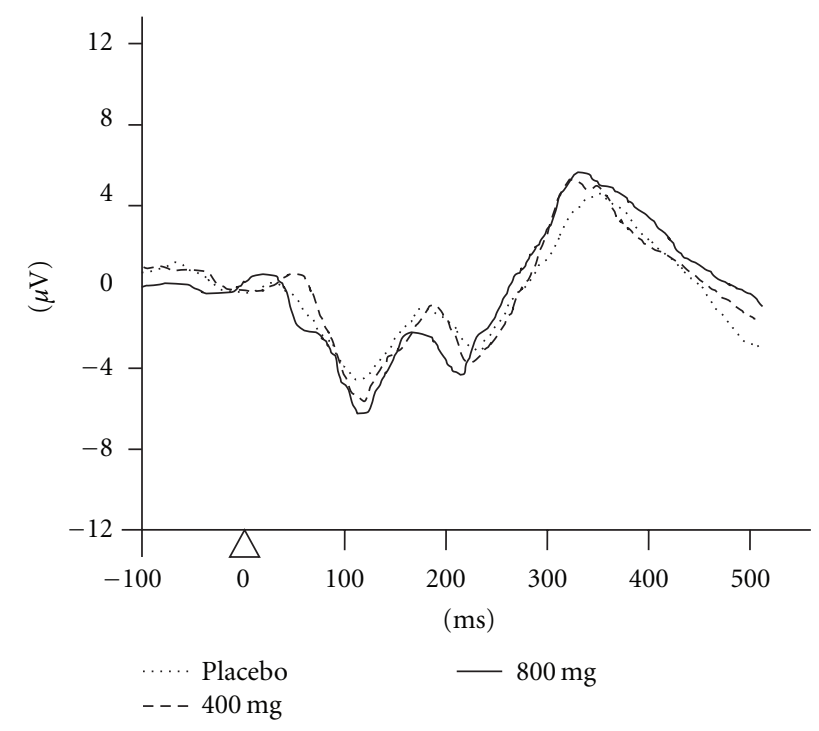

(c)

FIGURE 1: Average waveforms of the auditory event-related-potential at electrode $\mathrm{Cz}$ at various periods of treatment; (a) predose baseline, (b) 1st month after substance administration, and (c) 2nd month after substance administration.

parameters. Therefore, all subjects successfully met inclusion criteria and did not differ significantly.

3.2. Effect of Zingiber officinale on Event-Related Potential Components (ERPs). The grand average mean for all three conditions is shown in Table 2 and the average waveforms are shown in Figure 1. The predose baseline data of latency and amplitude for both the N100 and P300 of each group showed no significant difference $(F(2,57)=0.3765, P=$ $0.6879 ; F(2,57)=0.1865, P=0.8303 ; F(2,57)=0.0408$, $P=0.9600$ and $F(2,57)=0.0138, P=0.9863$, resp. $)$. After one month of treatment, the subjects who received Zingiber officinale at a dose of $800 \mathrm{mg}$ showed a significant increase in N100 amplitude $(t=3.3076, P=0.0010)$. After two months, participants who were given Zingiber officinale at doses of 400 and $800 \mathrm{mg}$ showed a significant increase in P300 amplitude $(t=2.4551, P=0.0094$ and $t=3.0716, P=$ 0.0020 , resp.). Furthermore, subjects who received Zinigber officinale at a dose of $800 \mathrm{mg}$ showed a significant increase in N100 amplitude and decreased P300 latency $(t=3.1847$, $P=0.0014$ and $t=3.6561, P=0.0004$, resp.).

3.3. Effect of Zingiber officinale on Working Memory. Prior to the determination of Zingiber officinale on working memory, baseline data and mean predose raw baseline scores for all three conditions (placebo, 400, and $800 \mathrm{mg}$ Zingiber officinale) for each individual task scores were subjected to a one-way ANOVA. No significant changes in any parameters were observed. 
TABLE 2: Effect of Zingiber officinale on auditory event-related potential.

\begin{tabular}{lcccc}
\hline \multirow{2}{*}{ Wave } & \multicolumn{2}{c}{ Predose baseline score } & \multicolumn{2}{c}{ Postdose score } \\
& \multicolumn{2}{c}{2 month } & $113.85 \pm 10.24$ \\
N100 & Placebo & $116.80 \pm 1.385$ & $114.50 \pm 11.97$ & $110.35 \pm 10.17$ \\
latency & $400 \mathrm{mg}$ & $114.35 \pm 11.44$ & $113.25 \pm 11.85$ & $106.75 \pm 9.13$ \\
\hline \multirow{2}{*}{ N100 } & $800 \mathrm{mg}$ & $114.05 \pm 8.31$ & $5.65 \pm 1.08$ & $5.70 \pm 1.07$ \\
amplitude & Placebo & $5.70 \pm 10.08$ & $6.40 \pm 1.18$ & $6.55 \pm 1.05$ \\
& $400 \mathrm{mg}$ & $5.90 \pm 1.37$ & $7.05 \pm 1.19^{* *}$ & $6.90 \pm 0.96^{* * *}$ \\
\hline \multirow{2}{*}{ P300 } & $800 \mathrm{mg}$ & $5.75 \pm 1.29$ & $330.30 \pm 11.02$ & $332.35 \pm 8.99$ \\
latency & Placebo & $332.70 \pm 12.96$ & $329.45 \pm 11.78$ & $323.85 \pm 13.10$ \\
& $400 \mathrm{mg}$ & $332.25 \pm 13.81$ & $325.60 \pm 12.91$ & $321.35 \pm 9.77^{* * *}$ \\
\hline \multirow{2}{*}{ amplitude } & $800 \mathrm{mg}$ & $332.90+10.20$ & $7.25 \pm 1.06$ & $7.20 \pm 1.05$ \\
& Placebo & $7.25 \pm 1.10$ & $7.50 \pm 1.23$ & $8.10 \pm 1.16^{* *}$ \\
\hline
\end{tabular}

The amplitudes and latencies of event-related potential elicited by oddball paradigm at Cz electrode were measured. Data are presented as mean \pm SD $(n=$ 20/group).

$* *, * * * P$ value $<0.05,0.01$, and 0.001 compared to placebo-treated group, respectively.

The mean raw baseline scores and changes from baseline factor scores for each condition across each session are presented in Table 3. It was found that participants who consumed Zingiber officinale at the dose of $800 \mathrm{mg} /$ day for one month showed a significant increase in \% accuracy of choice reaction time and numeric working memory $(t=$ 4.1014, $P=0.0001, t=1.9467, P=0.0295$, resp.). At two months of intervention, subjects who received Zingiber officinale at the dose of $400 \mathrm{mg} /$ day showed a significantly decreased reaction time for word recognition (msec.) $(t=$ 2.4000, $P=0.0107)$ while subjects who received Zingiber officinale at the dose of $800 \mathrm{mg} /$ day showed significant changes in \% accuracy of delayed word recognition, digit vigilance, choice reaction, numeric working memory and spatial working memory $(t=2.8799, P=0.0033 ; t=2.0904$, $P=0.0217 ; t=4.2279, P<0.0001 ; t=2.9313, P=0.0028$ and $t=3.0325, P=0.0022$, resp.). In addition, significant differences in numerous parameters including reaction time of the following: word recognition $(t=2.8204, P=0.0037)$ and choice reaction time $(t=2.1778, P=0.0178)$ were also observed in subjects who consumed Zingiber officinale at the dose of $800 \mathrm{mg} /$ day. Therefore, the current data suggests that the plant extract at doses used in this study especially Zingiber officinale at the dose of $800 \mathrm{mg} /$ day could improve working memory in all domains including (1) power of attention (obtained from reaction times of simple reaction time, choice reaction time, and digit vigilance tests), (2) the continuity of attention or accuracy of attention (indicated by the elevation of \% accuracy of the parameters mentioned above), (3) the speed of memory (indicated by the reaction time of simple reaction, digit vigilance, choice reaction, numeric working memory, picture recognition, and spatial working memory), and (4) quality of memory (indicated by the \% accuracy of the parameters mentioned in 3 ). All participants completed the trial for the whole period.
Moreover, no adverse effects after substance administration were observed.

\section{Discussion}

The present study clearly demonstrates that Zingiber officinale may enhance both the attention and cognitive processing in middle-aged women. Our event-related potential and computerized battery test (for assessing working memory) data showed that the improvement of cognitive function was observed in all attention and cognitive processing domains. During the last decade, numerous lines of evidence point out that event-related potential (ERP) components are sensitive to the attention and working memory demand of a task $[14,15]$. Previous studies show that stimuli that require active discrimination between classes of events typically evoke a large positive voltage deflection in the interval between 300 to $500 \mathrm{~ms}$ following the stimulus onset, which is known as P3 or P300 [16]. This component corresponds to mental processes such as recognition, categorization of stimuli, expectancy, or short-term memory. The amplitude of this wave is correlated with individual differences in working memory capacity [17]. P300 latency is regarded as a measurement of relative timing of the stimulus valuation process, indicating stimulus evaluating time [18]. Numerous brain regions including the temporal lobe, parietal lobe, and hippocampus have been proposed to be involved in its generation [19]. Recent findings show that the N100 reflects the process of attention activation, analysis of information based on the physical characteristics of sound, and the formation of memory trace with oscillators in the auditory cortex, prefrontal cortex, hippocampus, and cingulate cortex [20]. Moreover, the amplitude of N100 was also reported to be associated with enhanced memory performance [21], attention [22], expectancy [23], and tasks involving shortterm memory [24]. 
TABLE 3: Effect of Zingiber officinale on working memory assessing via computerized battery test.

\begin{tabular}{|c|c|c|c|c|}
\hline \multirow{2}{*}{ Measurement } & \multicolumn{2}{|c|}{ Predose baseline score } & \multicolumn{2}{|c|}{ Post-dose score } \\
\hline & & & 1 month & 2 months \\
\hline \multirow{3}{*}{ (1) Delay word recognition (\% accuracy) } & Placebo & $72.99 \pm 8.97$ & $73.88 \pm 9.25$ & $75.33 \pm 8.94$ \\
\hline & $400 \mathrm{mg}$ & $74.83 \pm 8.27$ & $75.83 \pm 8.58$ & $80.17 \pm 7.45$ \\
\hline & $800 \mathrm{mg}$ & $74.83 \pm 13.39$ & $79.00 \pm 12.14$ & $84.89 \pm 8.03^{* *}$ \\
\hline \multirow{3}{*}{$\begin{array}{l}\text { (2) Delay word recognition reaction time } \\
\text { (msec.) }\end{array}$} & Placebo & $1242.56 \pm 217.14$ & $1247.75 \pm 256.32$ & $1245.06 \pm 165.89$ \\
\hline & $400 \mathrm{mg}$ & $1226.06 \pm 161.82$ & $1221.45 \pm 176.35$ & $1120.67 \pm 111.2^{*}$ \\
\hline & $800 \mathrm{mg}$ & $1261.14 \pm 176.75$ & $1109.55 \pm 171.69$ & $1099.67 \pm 185.22^{* *}$ \\
\hline \multirow{3}{*}{ (3) Simple reaction time (msec.) } & Placebo & $619.05 \pm 222.35$ & $622.50 \pm 175.01$ & $625.15 \pm 161.96$ \\
\hline & $400 \mathrm{mg}$ & $616.25 \pm 195.39$ & $611.95 \pm 185.75$ & $596.30 \pm 126.60$ \\
\hline & $800 \mathrm{mg}$ & $623.25 \pm 191.43$ & $614.30 \pm 175.48$ & $573.95 \pm 177.20$ \\
\hline \multirow{3}{*}{ (4) Digit vigilance (\% accuracy) } & Placebo & $43.35 \pm 6.84$ & $42.90 \pm 7.95$ & $42.45 \pm 8.744$ \\
\hline & $400 \mathrm{mg}$ & $42.90 \pm 5.05$ & $43.45 \pm 9.93$ & $43.70 \pm 6.52$ \\
\hline & $800 \mathrm{mg}$ & $44.75 \pm 5.63$ & $44.65 \pm 6.45$ & $48.40 \pm 5.40^{*}$ \\
\hline \multirow{3}{*}{ (5) Digit Vigilance reaction time (msec.) } & Placebo & $631.65 \pm 140.92$ & $622.25 \pm 109.91$ & $626.60 \pm 122.24$ \\
\hline & $400 \mathrm{mg}$ & $620.00 \pm 122.74$ & $621.80 \pm 105.69$ & $594.70 \pm 83.15$ \\
\hline & $800 \mathrm{mg}$ & $623.75 \pm 109.55$ & $608.70 \pm 130.34$ & $587.40 \pm 71.65$ \\
\hline \multirow{3}{*}{ (6) Digit vigilance false alar number } & Placebo & $8.85 \pm 2.39$ & $8.7 \pm 1.55$ & $8.5 \pm 1.35$ \\
\hline & $400 \mathrm{mg}$ & $8.85 \pm 2.18$ & $8.25 \pm 1.61$ & $8.05 \pm 1.43$ \\
\hline & $800 \mathrm{mg}$ & $8.65 \pm 2.13$ & $7.35 \pm 1.34$ & $7.1 \pm 1.44^{* *}$ \\
\hline \multirow{3}{*}{ (7) Choice reaction time (\% accuracy) } & Placebo & $79.90 \pm 7.40$ & $81.70 \pm 6.68$ & $80.55 \pm 7.47$ \\
\hline & $400 \mathrm{mg}$ & $80.00 \pm 8.86$ & $84.95 \pm 9.23$ & $85.40 \pm 7.92$ \\
\hline & $800 \mathrm{mg}$ & $79.05 \pm 8.53$ & $89.95 \pm 8.26^{* *}$ & $90.00 \pm 7.82^{* * *}$ \\
\hline \multirow{3}{*}{ (8) Choice reaction time response (msec.) } & Placebo & $976.00 \pm 168.70$ & $964.25 \pm 100.98$ & $961.30 \pm 135.76$ \\
\hline & $400 \mathrm{mg}$ & $964.55 \pm 191.10$ & $944.80 \pm 128.93$ & $912.10 \pm 71.58$ \\
\hline & $800 \mathrm{mg}$ & $980.35 \pm 197.24$ & $915.90 \pm 72.00$ & $874.65 \pm 50.59^{*}$ \\
\hline \multirow{3}{*}{ (9) Numeric working memory (\% accuracy) } & Placebo & $73.90 \pm 10.40$ & $75.00 \pm 10.43$ & $74.70 \pm 10.54$ \\
\hline & $400 \mathrm{mg}$ & $75.50 \pm 8.67$ & $77.10 \pm 10.95$ & $81.35 \pm 9.57^{*}$ \\
\hline & $800 \mathrm{mg}$ & $76.45 \pm 9.69$ & $82.40 \pm 9.63^{*}$ & $85.00 \pm 8.72^{* *}$ \\
\hline \multirow{3}{*}{$\begin{array}{l}\text { (10) Numeric working memory reaction } \\
\text { time (msec.) }\end{array}$} & Placebo & $1334.50 \pm 226.25$ & $1348.29 \pm 209.25$ & $1335.70 \pm 203.13$ \\
\hline & $400 \mathrm{mg}$ & $1339.40 \pm 234.61$ & $1343.90 \pm 236.38$ & $1325.05 \pm 171.35$ \\
\hline & $800 \mathrm{mg}$ & $1335.60 \pm 260.95$ & $1337.10 \pm 170.24$ & $1313.95 \pm 138.71$ \\
\hline \multirow{3}{*}{ (11) Picture recognition (\% accuracy) } & Placebo & $72.99 \pm 8.97$ & $73.88 \pm 9.25$ & $75.33 \pm 8.94$ \\
\hline & $400 \mathrm{mg}$ & $74.83 \pm 8.27$ & $75.83 \pm 8.58$ & $80.17 \pm 7.45$ \\
\hline & $800 \mathrm{mg}$ & $74.83 \pm 13.39$ & $79.00 \pm 12.14$ & $84.89 \pm 8.03$ \\
\hline \multirow{3}{*}{$\begin{array}{l}\text { (12) Picture recognition reaction time } \\
\text { (msec.) }\end{array}$} & Placebo & $1256.88 \pm 239.51$ & $1247.75 \pm 156.32$ & $1245.06 \pm 165.89$ \\
\hline & $400 \mathrm{mg}$ & $1224.88 \pm 185.08$ & $1221.45 \pm 176.35$ & $1120.67 \pm 111.25$ \\
\hline & $800 \mathrm{mg}$ & $1234.61 \pm 197.52$ & $1109.55 \pm 171.96$ & $1099.67 \pm 185.22$ \\
\hline \multirow{3}{*}{ (13) Spatial working memory (\% accuracy) } & Placebo & $66.25 \pm 6.64$ & $66.13 \pm 5.39$ & $66.29 \pm 4.59$ \\
\hline & $400 \mathrm{mg}$ & $66.11 \pm 5.47$ & $66.95 \pm 5.47$ & $70.53 \pm 5.34^{* *}$ \\
\hline & $800 \mathrm{mg}$ & $66.33 \pm 6.88$ & $68.39 \pm 7.08$ & $71.77 \pm 4.12^{* *}$ \\
\hline \multirow{3}{*}{$\begin{array}{l}\text { (14) Spatial working memory reaction time } \\
\text { (msec.) }\end{array}$} & Placebo & $1799.25 \pm 33.45$ & $1817.30 \pm 203.17$ & $1844.10 \pm 232.15$ \\
\hline & $400 \mathrm{mg}$ & $1784.30 \pm 191.92$ & $1707.85 \pm 296.62$ & $1761.55 \pm 165.96$ \\
\hline & $800 \mathrm{mg}$ & $1712.75 \pm 219.45$ & $1695.75 \pm 200.13$ & $1704.40 \pm 309.16$ \\
\hline
\end{tabular}

Subjects were measured for power of attention, continuity of attention, speed of memory, and quality of memory by using computerized battery test. Data are presented as mean $\pm \mathrm{SD}(n=20$ /group).

$*, * *, * * * P$ value $<0.05,0.01$, and 0.001 compared to placebo-treated group, respectively. 


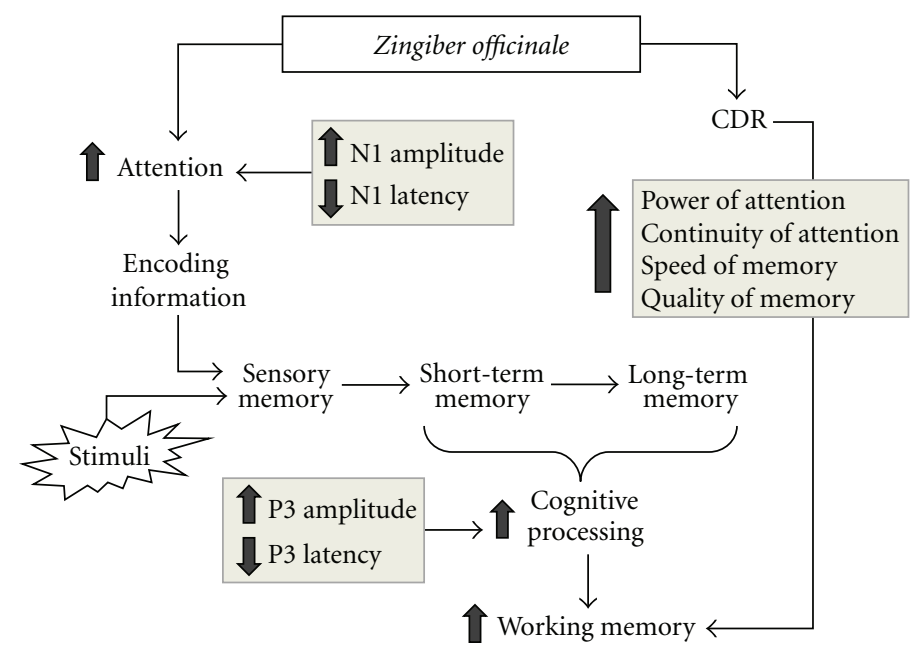

Figure 2: Effect of Zingiber officinale on attention, cognitive processing capabilities, and working memory of healthy, middle-aged women.

Several studies have also suggested that the high power of attention represents the intensity of concentration at a particular moment, with faster responses reflecting a higher focus of attention. It has been reported that the power of attention can be evaluated in choice reaction time and digit vigilance tests while the continuity of attention is also able to be evaluated using the \% accuracy tests mentioned earlier. In addition, the speed and quality of memory are also evaluated by using the reaction time and \% accuracy of numeric working memory, spatial memory, and word/picture recognition [25].

With regard to the assessment of working memory via the computerized battery test in accompany with the assessment of brain activity during cognitive performance, our results show that Zingiber officinale could enhance both attention and the efficiency of cognitive processing. However, the alteration in attention appears to be more sensitive to the effect of the plant extract rather than the cognitive processing. Previous studies report that the lateral prefrontal cortex (PFC) plays an important role in executive function such as planning, regulating behavior, and finding solutions to novel problems. Moreover, this area also contributes to the significant role of numeric working memory and is also critical for picture and word recognition process $[26,27]$. Recent findings also suggest an important role of the hippocampus in spatial working memory [28]. In addition, it was found that dopamine, and norepinephrine play a key role in numeric working memory including word and picture recognition (organized by the lateral PFC), while acetylcholine and serotonin in the hippocampus simultaneously were activated during spatial working memory tasks [29].

Zingiber officinale was previously reported to enhance the level of norepinephrine, epinephrine, dopamine and serotonin contents in the cerebral cortex and hippocampus [30]. Moreover, this plant extract and its active component, 6-gingerol, also inhibited the cholinesterase activity which in turn increased acetylcholine (ACh), a neurotransmitter that plays an important role in learning and memory [31].
A recent study demonstrated that ginger extract enhanced the memory performance induced by cerebral ischemia by decreasing infarct volume in both cortical and subcortical areas [6]. Therefore, taking all data together, we suggest that the cognitive enhancing effects of Zingiber officinale might be partly associated with the modulation effect of this plant extract on the alteration of both the monoamine system and the cholinergic system in various brain areas, including the prefrontal cortex and hippocampus.

Recent accumulating lines of evidence show that antioxidants could also improve cognitive performance in healthy elderly subjects $[32,33]$; therefore, the association between the antioxidant effects of Zingiber officinale and the cognitive enhancing effects still cannot be excluded $[6,34]$.

According to the cognitive enhancing effects of substances possessing antioxidant activity, the concentration of gingerol and shogaol of the extract, and the antioxidant activity of Zingiber officinale, we suggest that the cognitive enhancing effect of this plant extract on working memory observed in this study might be partly related to its antioxidant effect. However, the precise underlying mechanism and possible active ingredient responsible for the cognitive enhancing effect of Zingiber officinale still require further investigation.

Although the side effect of $Z$. officinale extract is rare which is corresponding with our data [35-37], some minor adverse effects at higher doses such as gastrointestinal disturbance, sleepiness, restlessness, sedation, and heartburn were also reported [38-40]. Moreover, the extract could therefore also possibly interact with medications including anesthesia, anticoagulants, and analgesics leading to arrhythmias, poor wound healing, bleeding, photosensitivity reaction, and prolonged sedation $[41,42]$. Therefore, the application in the mentioned conditions should be performed with caution.

\section{Conclusion}

The present study demonstrates that ginger extract enhances both attention and cognitive processing capabilities of 
healthy, middle-aged women, with no side effects reported. Therefore, our data reveal that Zingiber officinale extract is a potential brain tonic to enhance cognitive function for middle-age women (Figure 2). However, further study about the precise underlying mechanism especially the effect of the extract on the alteration of acetylcholine and monoamine transmitters should be performed.

\section{Acknowledgments}

This study was supported by The Integrative Complimentary Alternative Medicine Research Group, Khon Kaen University and Graduate School, Khon Kaen University, and Thailand Institute of Scientific and Technological Research, Pathum Thani. Moreover, the authors also would like to express sincere gratitude to Professor Keith Wesnes, and Cognitive Drug Research was acquired by United BioSource Corporation for initiating the development of computerized battery of cognitive tests.

\section{References}

[1] R. C. L. Fernandes, K. S. da Silva, C. Bonan, S. E. V. Zahar, and L. P. F. Marinheiro, "Cognitive function in menopausal women evaluated with the mini-mental state examination and word-list memory test," Cadernos de Saude Publica, vol. 25, no. 9, pp. 1883-1893, 2009.

[2] F. Mangialasche, M. C. Polidori, R. Monastero et al., "Biomarkers of oxidative and nitrosative damage in Alzheimer's disease and mild cognitive impairment," Ageing Research Reviews, vol. 8, no. 4, pp. 285-305, 2009.

[3] S. K. Verma and A. Bordia, "Ginger, fat and fibrinolysis," Indian Journal of Medical Sciences, vol. 55, no. 2, pp. 83-86, 2001.

[4] E. Langner, "Ginger: history and use," Advances in Therapy, vol. 15, no. 1, pp. 25-44, 1998.

[5] K. C. Srivastava and T. Mustafa, "Ginger (Zingiber officinale) in rheumatism and musculoskeletal disorders," Medical Hypotheses, vol. 39, no. 4, pp. 342-348, 1992.

[6] J. Wattanathorn, J. Jittiwat, T. Tongun, S. Muchimapura, and K. Ingkaninan, "Zingiber officinale mitigates brain damage and improves memory impairment in focal cerebral ischemic rat," Evidence-Based Complementary and Alternative Medicine, vol. 2011, Article ID 429505, 8 pages, 2011.

[7] B. H. Ali, G. Blunden, M. O. Tanira, and A. Nemmar, "Some phytochemical, pharmacological and toxicological properties of ginger (Zingiber officinale Roscoe): a review of recent research," Food and Chemical Toxicology, vol. 46, no. 2, pp. 409-420, 2008.

[8] F. T. Qiao, Y. Xu, R. Y. Y. Lam et al., "Diarylheptanoids and a monoterpenoid from the rhizomes of Zingiber officinale: antioxidant and cytoprotective properties," Journal of Natural Products, vol. 71, no. 1, pp. 12-17, 2008.

[9] D. O. Kennedy, A. B. Scholey, L. Drewery, V. R. Marsh, B. Moore, and H. Ashton, "Electroencephalograph effects of single doses of Ginkgo biloba and Panax ginseng in healthy young volunteers," Pharmacology Biochemistry and Behavior, vol. 75, no. 3, pp. 701-709, 2003.

[10] M. E. Drake, A. Pakalnis, and H. Padamadan, "Long-latency auditory event related potentials in migraine," Headache, vol. 29, no. 4, pp. 239-241, 1989.
[11] M. C. Moss, A. B. Scholey, and K. Wesnes, "Oxygen administration selectively enhances cognitive performance in healthy young adults: a placebo-controlled double-blind crossover study," Psychopharmacology, vol. 138, no. 1, pp. 27-33, 1998.

[12] K. A. Wesnes, "The use of cognitive tests to facilitate drug and dose selection in phase I and to optimize drug dosing in phase IV," International Congress Series, vol. 1220, pp. 35-50, 2001.

[13] G. Keppel, Design and Analysis. A Research Handbook, Prentice Hall, Upper Saddle River, NJ, USA, 1991.

[14] A. Gevins, M. E. Smith, J. Le et al., "High resolution evoked potential imaging of the cortical dynamics of human working memory," Electroencephalography and Clinical Neurophysiology, vol. 98, no. 4, pp. 327-348, 1996.

[15] L. K. McEvoy, M. E. Smith, and A. Gevins, "Dynamic cortical networks of verbal and spatial working memory: effects of memory load and task practice," Cerebral Cortex, vol. 8, no. 7, pp. 563-574, 1998.

[16] T. W. Picton, "The P300 wave of the human event-related potential," Journal of Clinical Neurophysiology, vol. 9, no. 4, pp. 456-479, 1992.

[17] H. Nittono, Y. Nageishi, Y. Nakajima, and P. Ullsperger, "Event-related potential correlates of individual differences in working memory capacity," Psychophysiology, vol. 36, no. 6, pp. 745-754, 1999.

[18] M. G. H. Coles, H. G. O. M. Smid, M. K. Scheffers, and L. J. Otten, "Mental chronometry and the study of human information processing," in Electrophysiology of Mind, M. D. Rugg and M. G. H. Coles, Eds., pp. 86-131, Oxford University Press, New York, NY, USA, 1995.

[19] S. Yamaguchi and R. T. Knight, "P300 generation by novel somatosensory stimuli," Electroencephalography and Clinical Neurophysiology, vol. 78, no. 1, pp. 50-55, 1991.

[20] V. E. Golimbet, I. S. Lebedeva, G. I. Korovaitseva, T. V. Lezheiko, and P. E. Yumatova, "Association of 5-HTTLPR serotonin transporter gene polymorphism and Val66Met brain-derived neurotrophic factor gene polymorphism with auditory N100 evoked potential amplitude in patients with endogenous psychoses," Bulletin of Experimental Biology and Medicine, vol. 146, no. 5, pp. 605-608, 2008.

[21] C. Papageorgiou, G. A. Giannakakis, K. S. Nikita, D. Anagnostopoulos, G. N. Papadimitriou, and A. Rabavilas, "Abnormal auditory ERP N100 in children with dyslexia: comparison with their control siblings," Behavioral and Brain Functions, vol. 5, article 26, 2009.

[22] T. W. Picton and S. A. Hillyard, "Human auditory evoked potentials. II. Effects of attention," Electroencephalography and Clinical Neurophysiology, vol. 36, no. 2, pp. 191-200, 1974.

[23] A. Starr, T. Aguinaldo, M. Roe, and H. J. Michalewski, "Sequential changes of auditory processing during target detection: motor responding versus mental counting," Electroencephalography and Clinical Neurophysiology, vol. 105, no. 3, pp. 201-212, 1997.

[24] L. Kaufman, S. Curtis, J. Z. Wang, and S. J. Williamson, "Changes in cortical activity when subjects scan memory for tones," Electroencephalography and Clinical Neurophysiology, vol. 82, no. 4, pp. 266-284, 1992.

[25] D. O. Kennedy, P. A. Jackson, C. F. Haskell, and A. B. Scholey, "Modulation of cognitive performance following single doses of $120 \mathrm{mg}$ Ginkgo biloba extract administered to healthy young volunteers," Human Psychopharmacology, vol. 22, no. 8, pp. 559-566, 2007.

[26] M. D’Esposito, B. R. Postle, D. Ballard, and J. Lease, "Maintenance versus manipulation of information held in working 
memory: an event-related fMRI study," Brain and Cognition, vol. 41, no. 1, pp. 66-86, 1999.

[27] E. E. Smith and J. Jonides, "Storage and executive processes in the frontal lobes," Science, vol. 283, no. 5408, pp. 1657-1661, 1999.

[28] M. B. Moser and E. I. Moser, "Distributed encoding and retrieval of spatial memory in the hippocampus," The Journal of Neuroscience, vol. 18, no. 18, pp. 7535-7542, 1998.

[29] R. Stancampiano, S. Cocco, C. Cugusi, L. Sarais, and F. Fadda, "Serotonin and acetylcholine release response in the rat hippocampus during a spatial memory task," Neuroscience, vol. 89, no. 4, pp. 1135-1143, 1999.

[30] A. M. Waggas, "Neuroprotective evaluation of extract of ginger (Zingiber officinale) root in monosodium glutamateinduced toxicity in different brain areas male albino rats," Pakistan Journal of Biological Sciences, vol. 12, no. 3, pp. 201212, 2009.

[31] M. N. Ghayur, A. H. Gilani, T. Ahmed et al., "Muscarinic, $\mathrm{Ca}(++)$ antagonist and specific butyrylcholinesterase inhibitory activity of dried ginger extract might explain its use in dementia," The Journal of Pharmacy and Pharmacology, vol. 60, no. 10, pp. 1375-1383, 2008.

[32] W. J. Perrig, P. Perrig, and H. B. Stahelin, "The relation between antioxidants and memory performance in the old and very old," Journal of the American Geriatrics Society, vol. 45, no. 6, pp. 718-724, 1997.

[33] S. C. Monteiro, C. Matté, C. S. Bavaresco, C. A. Netto, and A. T. S. Wyse, "Vitamins E and C pretreatment prevents ovariectomy-induced memory deficits in water maze," Neurobiology of Learning and Memory, vol. 84, no. 3, pp. 192-199, 2005.

[34] V. Asnani and R. J. Verma, "Antioxidative effect of rhizome of Zingiber officinale on paraben induced lipid peroxidation: an in vitro study," Acta Poloniae Pharmaceutica, vol. 64, no. 1, pp. 35-37, 2007.

[35] H. Kobayashi, N. Mizuno, H. Teramae et al., "Diet and Japanese herbal medicine for recalcitrant atopic dermatitis: efficacy and safety," Drugs under Experimental and Clinical Research, vol. 30, no. 5-6, pp. 197-202, 2004.

[36] F. Borrelli, R. Capasso, G. Aviello, M. H. Pittler, and A. A. Izzo, "Effectiveness and safety of ginger in the treatment of pregnancy-induced nausea and vomiting," Obstetrics and Gynecology, vol. 105, no. 4, pp. 849-856, 2005.

[37] C. H. Oliveira, M. E. A. Moraes, M. O. Moraes, F. A. F. Bezerra, E. Abib, and G. De Nucci, "Clinical toxicology study of an herbal medicinal extract of Paullinia cupana, Trichilia catigua, Ptychopetalum olacoides and Zingiber officinale (Catuama ${ }^{\circledR}$ ) in healthy volunteers," Phytotherapy Research, vol. 19, no. 1, pp. 54-57, 2005.

[38] S. Manusirivithaya, M. Sripramote, S. Tangjitgamol et al., "Antiemetic effect of ginger in gynecologic oncology patients receiving cisplatin," International Journal of Gynecological Cancer, vol. 14, no. 6, pp. 1063-1069, 2004.

[39] M. Sripramote and N. Lekhyananda, "A randomized comparison of ginger and vitamin B6 in the treatment of nausea and vomiting of pregnancy," Journal of the Medical Association of Thailand, vol. 86, no. 9, pp. 846-853, 2003.

[40] O. Betz, P. Kranke, G. Geldner, H. Wulf, and L. H. J. Eberhart, "Is ginger a clinically relevant antiemetic? A systematic review of randomized controlled trials," Forschende Komplementarmedizin und Klassische Naturheilkunde, vol. 12, no. 1, pp. 14-23, 2005.
[41] J. O. Ciocon, D. G. Ciocon, and D. J. Galindo, "Dietary supplements in primary care: botanicals can affect surgical outcomes and follow-up," Geriatrics, vol. 59, no. 9, pp. 20-24, 2004.

[42] P. Krüth, E. Brosi, R. Fux, K. Mörike, and C. H. Gleiter, "Ginger-associated overanticoagulation by phenprocoumon," Annals of Pharmacotherapy, vol. 38, no. 2, pp. 257-260, 2004. 


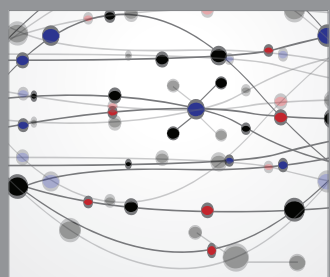

The Scientific World Journal
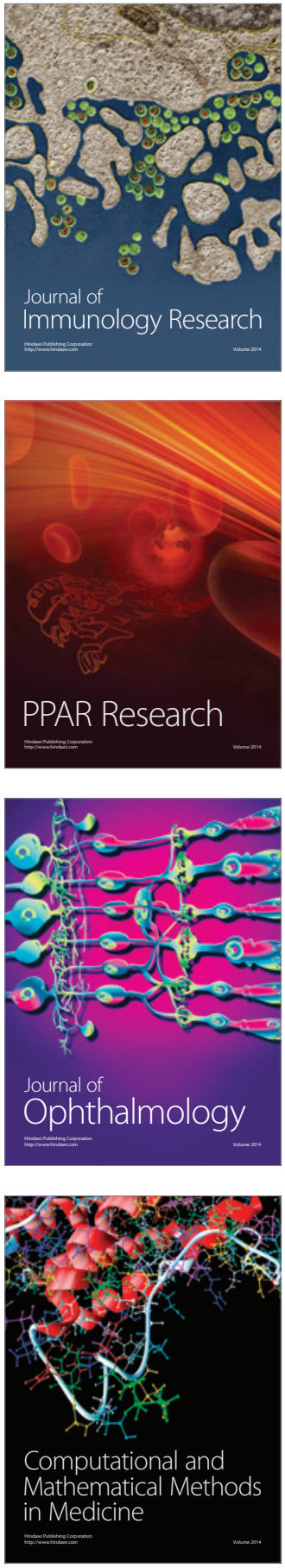

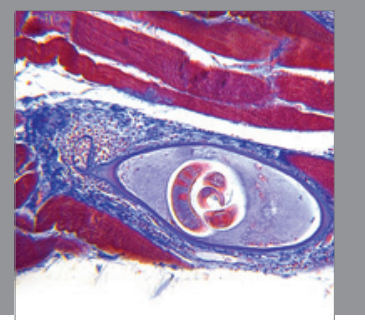

Gastroenterology

Research and Practice
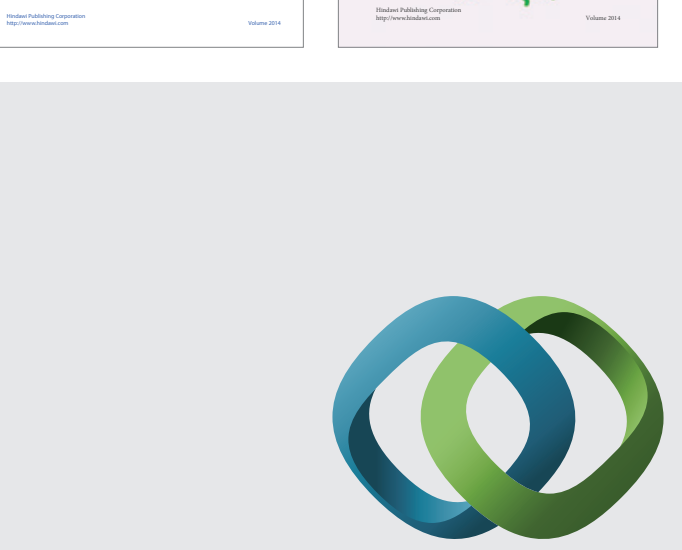

\section{Hindawi}

Submit your manuscripts at

http://www.hindawi.com
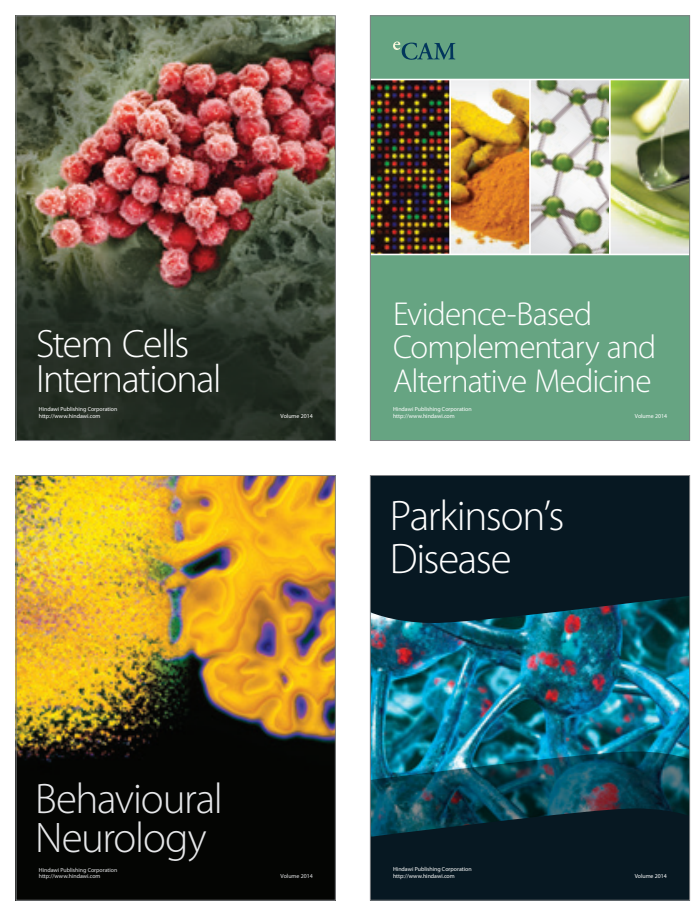

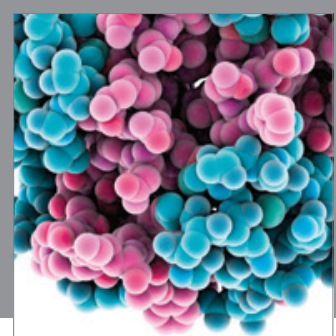

Journal of
Diabetes Research

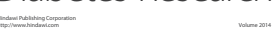

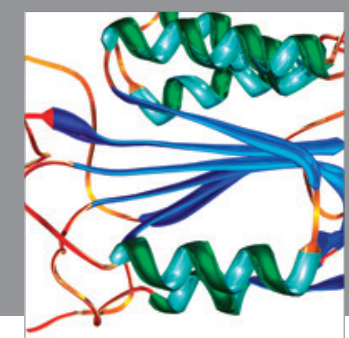

Disease Markers
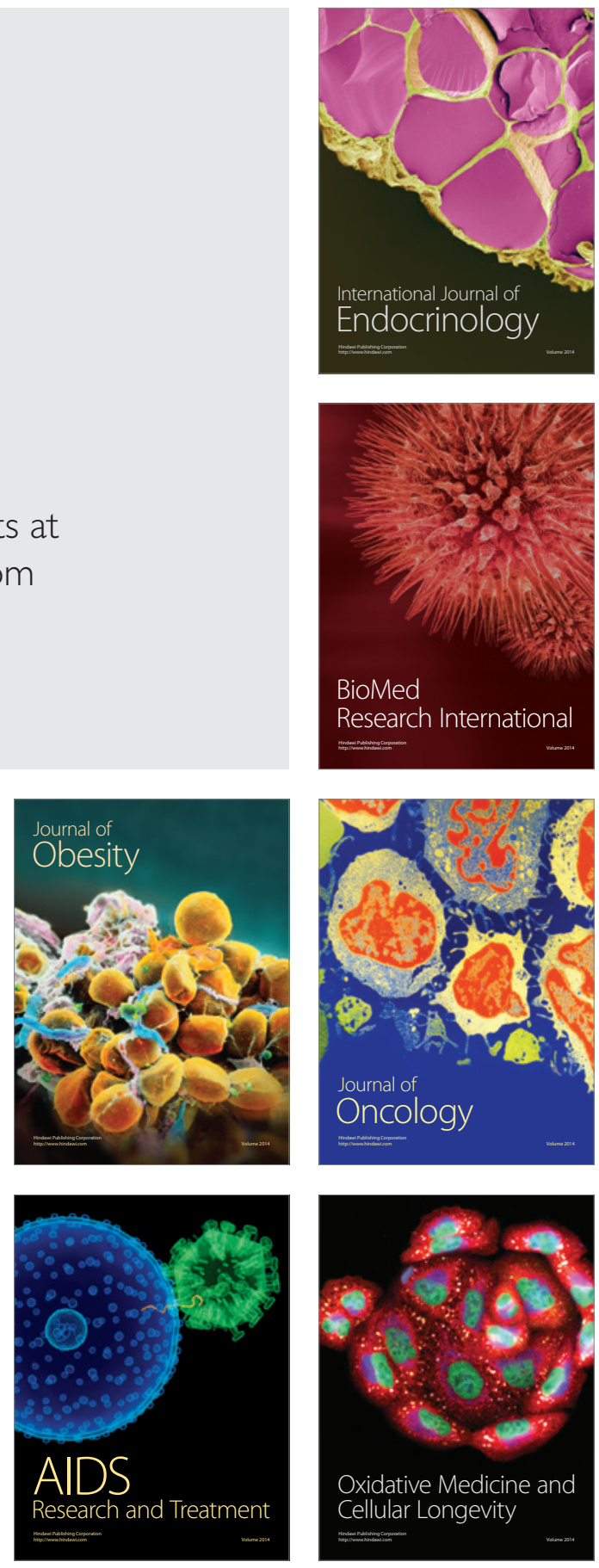